\title{
O texto filosófico nas aulas de Filosofia do Ensino Médio: análise e proposição a partir da experiência paranaense
}

\author{
professor da Universidade Federal do Paraná \\ Rui Valese
}

professor do C. E. D. Arnaldo F. Busato - UFPR

\section{RESUMO}

A volta da Filosofia ao Ensino Médio impõe o desafio de legitimá-la como matéria escolar. A pergunta que aqui se pretende responder - qual o sentido e lugar que o texto clássico de Filosofia ocupa na aula de Filosofia no Ensino Médio? - tem relação com o processo de transposição didática do saber filosófico. Considerando essa problemática pretende-se: mostrar como o texto filosófico é tratado no curso de Filosofia da Universidade Federal do Paraná e, nas Diretrizes de Filosofia e no Livro Didático Público de Filosofia do Paraná; argumentar em favor do uso apropriado e cuidadoso do texto filosófico; apresentar alguns cuidados na escolha do texto e algumas orientações sobre o uso do mesmo nas aulas de Filosofia.

Palavras-chave: Ensino de Filosofia, Texto Filosófico, Transposição Didática.

\begin{abstract}
The return of Philosophy in the Secondary Education imposes the challenge of legitimizing it as a school subject. The question which is intended to be responded here - what is the meaning and the place in which the classic text of Philosophy occupies in a Secondary School Philosophy class? - is related to the process of didactic transposition of philosophical knowledge. Given this problem it is intended: to show how the philosophical text is treated in the Philosophy course at Federal University of Paraná, in the Guidelines for Philosophy and the Public Philosophy Textbook of Paraná; to argue in favor of a careful and appropriate use of the philosophical text; to present some care in selecting the text and some guidance on its use in the Philosophy classes.
\end{abstract}

Keywords: Teaching Philosophy, Philosophical Text, Didactic Transposition.

Filosofia e Educação - ISSN 1984-9605 - v. 4, no 1, abril-setembro de 2012 


\section{Introdução}

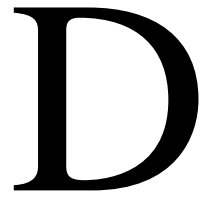

epois de alguns anos de luta pela inclusão da Filosofia como disciplina obrigatória nos currículos escolares, um avanço histórico ocorre com sua aprovação nas três séries do Ensino Médio, bem como nos quatro anos dos cursos profissionalizantes em todo território nacional ${ }^{1}$. Sem sombra de dúvida, foi uma vitória marcada pela participação de boa parte da sociedade civil organizada e, principalmente, de estudantes e professores de Filosofia. O desafio a ser enfrentado agora é de outra natureza: como tornar legítima a presença da Filosofia não como apenas mais uma disciplina curricular ao lado das outras, mas como um saber que pretende contribuir para a formação dos adolescentes e dos jovens que frequentam os bancos escolares.

O principal objetivo deste texto é mostrar qual é o sentido e lugar que o texto clássico de Filosofia ocupa numa aula de Filosofia no Ensino Médio. Toma-se como referência a experiência dos últimos anos em curso nas escolas públicas paranaenses. As reflexões são realizadas a partir da análise e da triangulação de três campos empíricos, a saber: a proposta curricular do curso de Filosofia da Universidade Federal do Paraná (UFPR), o texto das Diretrizes Curriculares de Filosofia e o Livro Didático Público.

O modo como o texto pode ser tratado nas aulas de Filosofia está intrinsecamente ligado à problemática mais ampla acerca do processo de transposição didática, isto é, tem a ver com aquilo que o professor considera ou não como elemento necessário para ensinar Filosofia; se o professor compreende, do ponto de vista do ensino, a Filosofia como filosofia, como um saber que tem uma terminologia própria que a caracteriza como uma área do conhecimento.

\footnotetext{
${ }^{1}$ Em junho de 2008 o Congresso Nacional aprovou a lei que altera o artigo $36 \mathrm{da}$ LDB 9394/96 tornando a Filosofia e a Sociologia disciplinas obrigatórias do currículo do Ensino Médio.
}

Filosofia e Educação - ISSN 1984-9605 - v. 4, no 1, abril-setembro de 2012 
A pesquisa realizada (HORN, 2002) com 228 professores de Filosofia da rede pública de ensino do Paraná mostra a importância que o texto ocupa nas aulas de Filosofia. Quando interrogados sobre a forma como os alunos participam das aulas, $83,3 \%$ dos professores indicam a leitura de textos em sala como estratégica para as discussões e debates, ou seja, como meio privilegiado de participação dos alunos.

O uso de uma linguagem, a mais próxima possível daquela utilizada pelo jovem, permite pensar critérios para interpretação, escolha e decisão à luz de um pensar universalizante próprio da filosofia. Isso significa que filosofar com o cotidiano do aluno a partir da música, dos jornais, das poesias, enfim, com o universo cultural do jovem, não significa abandonar ou perder de vista o texto filosófico — acadêmico —, mas, ao contrário, introduzi-lo conscientemente como referência para a reflexão filosófica. Não é preciso, necessariamente, partir do texto filosófico, mas é preciso de um jeito ou de outro - chegar a ele. (HORN, 2002)

Considerando essa problemática, pretende-se argumentar:

a) em defesa do uso apropriado e cuidadoso do texto filosófico, de modo que cumpra sua função mediadora na reflexão teórica;

b) a favor de alguns cuidados na escolha do texto, tais como: adequação ao conteúdo que se estiver estudando; o grau de dificuldade que o mesmo apresenta; o tempo despendido para a sua leitura, interpretação e síntese;

c) em defesa de algumas orientações sobre a necessidade e o uso do texto filosófico como tecnologia central, mas não única, das aulas de Filosofia. Mostrar que a leitura, a análise e a interpretação do texto filosófico são elementos imprescindíveis tanto para o "ensinar Filosofia", quanto para o "aprender a filosofar", e não um fim em si mesmo.

Filosofia e Educação - ISSN 1984-9605 - v. 4, no 1, abril-setembro de 2012 
Pode-se considerar que é entendimento comum, presente nos currículos dos cursos de licenciatura em Filosofia ${ }^{2}$, o fato de se formar um professor que, além de possuir ampla compreensão da filosofia entre as competências exigidas, consiga desenvolver bem com seus alunos a análise, a interpretação e o comentário de textos filosóficos clássicos, decorrendo daí o domínio e a compreensão de conceitos produzidos no âmbito da Filosofia desde seu surgimento como saber. Tanto as bibliografias previstas como as ementas das disciplinas contemplam o trabalho com autores e textos clássicos referentes às temáticas filosóficas, bem como o trabalho de apoio com textos de comentadores relevantes. No caso da UFPR, há a oferta de ao menos duas matérias obrigatórias cuja ênfase é a leitura e a análise de textos filosóficos.

\section{O texto filosófico no ensino de Filosofia}

Pode-se dizer com certa segurança que se tornou lugar-comum nos círculos acadêmicos e nos debates sobre o ensino da Filosofia a defesa do uso do texto filosófico nas aulas de Filosofia do Ensino Médio. O que certamente não constitui unanimidade é o modo como essa apropriação deve ser realizada, seja do ponto de vista dos critérios para seleção dos textos, seja do modo como os mesmos devem ser tratados do ponto de vista da transposição didática.

Para compreender essa questão buscou-se inicialmente diagnosticar os espaços e lugares em que essa problemática se inscreve institucionalmente e se expressa como "prática social de referência" tanto para a formação inicial, quanto para a formação continuada dos professores. Para tanto, fez-se necessário estabelecer um nexo entre esses campos de

${ }^{2}$ A tese "Por uma mediação praxiológica do saber filosófico no Ensino Médio: análise e proposição a partir da experiência paranaense", de Geraldo Balduino Horn, de 2002, apresenta um panorama sobre os cursos de licenciatura em Filosofia no Paraná reconhecidos e credenciados pelo MEC, entre eles o curso de Filosofia da UFPR.

Filosofia e Educação - ISSN 1984-9605 - v. 4, no 1, abril-setembro de 2012 
formação e orientação da prática pedagógica do professor. Tomou-se como campo empírico para análise, o curso de bacharelado e licenciatura em Filosofia da UFPR, as Diretrizes Curriculares atuais (2009) e o Livro Didático Público de Filosofia produzido no âmbito da política da Secretaria da Educação do Estado do Paraná.

\section{A compreensão sobre o uso do texto no curso de Filosofia da UFPR}

O curso de Filosofia da UFPR, em vigor desde 1999, apresenta em sua grade curricular matérias como Seminários de Leitura, Análise e Produção de Textos Filosóficos I e Seminários de Leitura, Análise e Produção de Textos Filosóficos II, voltadas especificamente à produção de textos com o objetivo de contribuir para a formação geral do futuro bacharel e licenciado em Filosofia. São as disciplinas de iniciação à prática do filosofar; visam dar ao aluno um primeiro contato com as diferentes formas do trabalho reflexivo. Oferecidas no primeiro ano, todos os alunos devem obrigatoriamente cursá-las e são pré-requisito para a matrícula em outras disciplinas na continuidade do Curso.

Uma análise mais atenta da estrutura do currículo nos leva à constatação de que ele privilegia de modo especial as atividades de pesquisa, tidas como pano de fundo essencial na formação do aluno. Essa perspectiva é confirmada nas palavras de Eva (2001), ao comentar os pontos que diferenciam o atual currículo do anterior:

Isso exige que o aluno possa aprender, de algum modo, a pensar com os autores filosóficos aos quais será exposto, o que só pode ser feito através do exame direto dos textos desses filósofos, pelo qual se pretenderá tentar reconstituir cuidadosa e rigorosamente as questões próprias que o próprio filósofo formula, o modo como as enfrenta, os argumentos que considera, as respostas que formula, os limites que encontra, etc.

Filosofia e Educação - ISSN 1984-9605 - v. 4, no 1, abril-setembro de 2012 
O primeiro problema a ser levantado é que esse trabalho rigoroso de pesquisa do aluno não parece diretamente relacionado à atividade por excelência do licenciado, ou seja, como se dá o uso do texto para ministrar aulas de Filosofia no Ensino Médio com excelência acadêmica...

Encontramos na análise de Eva (2001), uma reflexão que parece muito apropriada:

Mas é também essencial que, ao menos a médio prazo, os alunos de filosofia do secundário passem, na aula de filosofia, a estudar filosofia (a estudar, mesmo que através de estratégias pedagogicamente propícias, os próprios textos dos filósofos, daqueles autores que qualquer pessoa que sabe um pouco o que é filosofia reconhece como filósofos: Platão, Aristóteles, Descartes, Hobbes, Popper, Marx, Hegel, Comte, etc.)

Partindo do exposto por Eva é preciso interrogar, portanto, quais são essas "estratégias pedagogicamente propícias" e onde o aluno licenciando as apreende, uma vez que é muito complicado exigir de um aluno do Ensino Médio a capacidade de leitura e interpretação de textos filosóficos (com algum rigor) sem ter antes recebido qualquer tipo de iniciação às especificidades, digamos, técnicas, exigidas sobremaneira - como tão bem sabemos - no estudo e investigação das principais correntes do pensamento filosófico ocidental.

Apesar desse questionamento é possível depreender a partir da proposta curricular que o estudante de Filosofia tem, sim, na sua trajetória de formação uma clara ênfase de como ler e sistematizar um texto de natureza filosófica.

\section{A compreensão do uso do texto nas Diretrizes Curriculares}

O documento das Diretrizes Curriculares de Filosofia da rede pública de ensino do Paraná desde sua primeira versão, em 2006, mostra

Filosofia e Educação - ISSN 1984-9605 - v. 4, no 1, abril-setembro de 2012 
uma clara posição quanto ao uso do texto clássico nas aulas de Filosofia do Ensino Médio. Não se trata apenas de uma indicação ou uma recomendação ao professor de Filosofia, mas de uma orientação com explícito caráter didático e pedagógico. No encaminhamento metodológico quando apresenta para o professor os quatros momentos ${ }^{3}$ do trabalho com os conteúdos estruturantes, no segundo - da problematização -, destaca a importância do texto filosófico:

Ao problematizar, o professor convida o estudante a analisar o problema, o qual se faz por meio da investigação, que pode ser o primeiro passo para possibilitar a experiência filosófica. É imprescindivel recorrer à história da Filosofia e aos textos clássicos dos filósofos ${ }^{4}$, pois neles o estudante se defronta com o pensamento filosófico, com diferentes maneiras de enfrentar o problema e, com as possíveis soluções já elaboradas, as quais orientam e dão qualidade à discussão (PARANÁ, 2008, p. 60).

Não se trata de uso contingente do texto, mas de maneira “imprescindível” para o processo de investigação filosófica. Pode-se dizer que o exposto nas Diretrizes em relação ao uso do texto como tecnologia central da aula tem a pretensão de estabelecer uma linha divisória de tudo o que já se disse e se publicou em termos de documentos oficiais acerca do ensino da Filosofia no Paraná, principalmente, em relação à proposta elaborada e publicada em $1994^{5}$.

Como o uso do texto nas aulas de Filosofia é concebido pelo atual documento das Diretrizes Curriculares? De modo geral, pode-se afirmar

3 Momentos do encaminhamento metodológico: a) mobilização; b) problematização; c) sistematização; d) criação de conceito

${ }^{4}$ Sem grifo no original.

${ }^{5}$ Em 1994 a equipe pedagógica da SEED elaborou uma proposta para a área de Filosofia que contou com a consultoria, entre outros consultores, do professor e Celso F. Favaretto, da FEUSP.

Filosofia e Educação - ISSN 1984-9605 - v. 4, no 1, abril-setembro de 2012 
que o texto é compreendido em ao menos três sentidos diferentes ${ }^{6}$, mas interligados entre si: a) o uso do texto indicado como centro do processo pedagógico, como uma tecnologia sem a qual não se pode falar em aula de Filosofia; b) como recurso necessário, no entanto, sem indicar como tratar um texto filosófico do ponto de vista didático-pedagógico, muito menos de modo filosófico; ou seja, não estabelece nenhuma orientação em relação à análise de textos; c) indicado como referência apontando para alguns cuidados como não tomar o texto como fim, não estabelecer uma leitura linear, formal ou simplesmente cadastrada.

Para identificar com mais precisão o que estamos afirmando, vejamos algumas passagens das Diretrizes que tratam da classificação acima adotada. Em relação ao primeiro aspecto: do uso do texto como tecnologia central, destacamos alguns trechos que elucidam bem esse sentido ${ }^{7}$ :

[...] meio da leitura dos textos filosóficos, espera-se que o estudante possa pensar, discutir, argumentar e, que, nesse processo, crie e recrie para si os conceitos filosóficos, ciente de que não há conceito simples (PARANÁ, 2008, p.51).

A atividade filosófica centrada, sobretudo no trabalho com o texto, propiciará entender as estruturas lógicas e argumentativas, levando-se em conta o cuidado com a precisão dos enunciados, com o encadeamento e clareza das ideias e buscando a superação do caráter fragmentário do conhecimento (PARANÁ, 2008, p 53).

No Ensino Médio, a Filosofia Política [conteúdo estruturante], por meio dos textos filosóficos, tem por objetivo problematizar conceitos como o de cidadania, democracia, soberania, justiça, igualdade e liberdade, dentre

\footnotetext{
${ }^{6}$ A classificação adotada e a ordem de apresentação obedeceram, basicamente, dois critérios, quais sejam: a) palavras/expressões presentes no próprio texto das Diretrizes; b) a classificação segue a ordem crescente tal como aparece no texto.

${ }^{7}$ As expressões ou trechos destacados em negrito nos excertos das Diretrizes ao longo texto, não estão no texto original, são de responsabilidade dos autores.
}

Filosofia e Educação - ISSN 1984-9605 - v. 4, no 1, abril-setembro de 2012 
outros, de maneira a preparar o estudante para uma ação política consciente e efetiva (PARANÁ, 2008, p 58).

É possível observar que o texto se inscreve como fator sine qua non do ensino de Filosofia. Ele assume uma condição necessária para que o exercício do filosofar ocorra efetivamente. Isto é, o texto deve ser tomado como instrumento mediador do processo de argumentação, de discussão e do pensar sistemático voltado, em última instância, ao sentido essencial de toda e qualquer atividade filosófica, que é a elaboração de conceitos.

A reflexão filosófica centrada no trabalho com o texto também contribui substantivamente para a formação não só do leitor crítico, como da autoria de textos e escritos de caráter filosófico, ou seja, na produção de textos com estrutura lógica e argumentativa, bem como clareza no entendimento das ideias e na produção conceitual. A leitura e sistematização de textos filosóficos para além da inteligibilidade têm ainda outra função: a de permitir com que o estudante possa posicionar-se frente às polêmicas existenciais e problemas sociais e políticos que o cotidiano se lhes apresenta.

Já em relação ao segundo ponto da classificação, ou seja, o texto como recurso importante e necessário, há várias passagens sem que nenhuma orientação quanto a seu uso seja afirmado:

[...] não se trata de abandonar a história da Filosofia, pois a opção por conteúdos estruturantes compreende também o trabalho com os textos clássicos dos filósofos (PARANÁ, 2008, p.42).

[...] da década de 1980 até hoje, os professores de filosofia vêm manifestando uma preocupação com o conteúdo e a metodologia, em outras palavras, a necessidade de pensar a relação entre os textos filosóficos e a experiência filosófica no ensino médio (PARANÁ, 2008, p.47).

Filosofia e Educação - ISSN 1984-9605 - v. 4, no 1, abril-setembro de 2012 
[...] os conteúdos estruturantes devem ser trabalhados na perspectiva de fazer com que os estudantes pensem os problemas com significado histórico e social e analisem a partir dos textos filosóficos que lhes forneçam subsídios para que pesquisem, façam relações e criem conceitos (PARANÁ, 2008, p. 52).

A ênfase nesse caso é mais de ordem interna, de justificação da Filosofia como uma área do conhecimento humano e como uma disciplina escolar. Não há disciplina sem estatuto de conhecimento. A pergunta a ser feita, portanto, é: por um lado, como a filosofia se constitui como conhecimento e, por outro, como se institui como um saber a ser ensinado? É nisso que reside, praticamente, o argumento da importância e da necessidade do uso do texto como garantia da transposição do saber filosófico escolar. Por isso o entendimento, hoje, também lugar-comum, de que a História da Filosofia, o tema/problema filosófico e o texto são elementos comuns de um mesmo problema: como ensinar Filosofia? Um não elimina o outro; muito pelo contrário, um não existe sem o outro quando se pensa em termos de ensino.

Há que se destacar também a relação que as Diretrizes estabelecem entre o uso do texto e a pesquisa. Em tempos de democratização da informação via Internet, eventos e ampliação dos investimentos públicos em materiais didáticos e textos clássicos no caso da Filosofia, principalmente, o incentivo e as atividades voltadas à pesquisa tornaram-se um dos elementos centrais do processo pedagógico. Neste sentido, o ato de pesquisar tem uma relação intrínseca com o modus vivendi histórico de se fazer Filosofia.

Quanto ao terceiro aspecto apontado, ou seja, do uso do texto como referência, as Diretrizes sugerem tomar cuidado para não transformá-lo como um fim em si mesmo, realizando uma exegese textual que pouco contribuirá à formação de leitores críticos.

Filosofia e Educação - ISSN 1984-9605 - v. 4, no 1, abril-setembro de 2012 
É preciso que o professor tenha uma ação consciente para não praticar uma leitura em que o texto seja um fim em si mesmo. O domínio do texto é necessário. O problema está no formalismo e no tecnicismo estrutural da leitura, que desconsidera, quando não descarta, a necessidade da compreensão do contexto histórico, social e político de sua produção, como também de sua própria leitura (PARANÁ, 2008, p 53).

Estas Diretrizes Curriculares, ao procurarem superar a concepção enciclopédica da Filosofia, não desvalorizam os textos que possam ser trabalhados ao longo do percurso filosófico (PARANÁ, 2008, p. 55-56).

É importante ressaltar que os recursos escolhidos para tal mobilização filme, música, texto e outros - podem ser retomados a qualquer momento do processo de aprendizagem (PARANÁ, 2008, 60).

O ensino de Filosofia deverá dialogar com os problemas do cotidiano, com o universo do estudante... tomando como referência os textos filosóficos clássicos e seus comentadores (PARANÁ, 2008, p.67).

Pode-se cair facilmente no textualismo, num reducionismo que implica o risco de entender que a formação filosófica só se dá mediante o domínio técnico dos textos. Não que este domínio não tenha importância, muito pelo contrário, é um dos elementos centrais do processo de apropriação dos conteúdos filosóficos. O problema está em se reduzir à compreensão formal do texto. Portanto, não se trata de descartar a necessidade do domínio técnico do texto, pois quando se está diante do texto filosófico busca-se compreendê-lo a partir de seu contexto. Há uma tendência de refugiar-se na tecnicidade estrutural do texto desconsiderando, quando não eliminando ou descartando a necessidade do diálogo entre o conhecimento que o texto transmite, o contexto histórico social no qual está imerso e as condições de subjetividade de quem busca sua apropriação, seja o aluno, seja o professor (HORN, 2002).

Filosofia e Educação - ISSN 1984-9605 - v. 4, no 1, abril-setembro de 2012 


\section{A compreensão do uso do texto no Livro Público}

Uma primeira distinção a ser feita sobre a presença do texto filosófico num material didático é sobre sua natureza. Basicamente podemos distinguir duas formas de sua presença: a) como citação curta, no corpo de um texto discursivo sobre determinada questão filosófica, ou em destaque, como uma citação longa; b) ou ainda como fragmento de um texto, podendo ser curto ou longo. A diferença básica entre as duas situações é que, quando citação, seu caráter é de ilustração, complementação de um raciocínio que está sendo desenvolvido. No segundo caso, quando for como fragmento, o mesmo é central, e não secundário.

Outra observação necessária se refere à presença de textos clássicos ou de comentadores. Não que se desmereça o trabalho de alguém que se tenha especializado no pensamento de um determinado filósofo; no entanto o mesmo deve servir ou como primeiro passo, ou como passo complementar, nunca como único meio de compreensão do pensamento de um referido filósofo. Enquanto o comentador é auxiliar no processo de compreensão de um conceito no pensamento de um filósofo, o texto clássico é a busca pelo entendimento do conceito direto na fonte ou pode ser o próprio objeto de investigação.

O LDP $^{8}$ está dividido em seis conteúdos estruturantes: Mito e Filosofia, Teoria do Conhecimento, Ética, Filosofia Política, Filosofia da Ciência e Estética. Cada conteúdo estruturante é subdividido em três ou quatro capítulos.

A primeira "aparição" de um texto filosófico no LDP é já na "carta" aos estudantes. Trata-se de um fragmento de Arendt (A condição humana), em que a filósofa fala sobre o agir humano, que é individual e singular; e sobre o discurso humano como efetivação e distinção da ação humana, sem

\footnotetext{
${ }^{8}$ Livro Didático Público.
}

Filosofia e Educação - ISSN 1984-9605 - v. 4, no 1, abril-setembro de 2012 
acrescentar nada com relação ao uso do texto filosófico clássico ao longo do livro.

$\mathrm{Na}$ Apresentação, no $3^{\circ}$ parágrafo, anuncia que o conteúdo será problematizado "com o auxílio dos textos filosóficos". Mais adiante, no parágrafo $5^{\circ}$, anuncia a leitura de textos, sem especificar que tipo de texto será utilizado. No $7^{\circ}$ parágrafo, sugere a leitura de textos clássicos, sem, no entanto, dizer como o mesmo aparece no LDP, ou que será feita uma lista de referência, ou que o professor pode montar sua coletânea de textos; apenas que "muitas dessas obras" estão disponíveis na internet, sem dizer quais são essas obras. Por último, ainda na Apresentação, no parágrafo $8^{\circ}$, informa que o texto filosófico é parte integrante do processo proposto, que deve ser percorrido com "o tempo necessário".

$\mathrm{Na}$ introdução do conteúdo estruturante Mito e Filosofia, não há a indicação de que serão utilizados textos filosóficos, ainda que o faça ao longo do mesmo. No conteúdo estruturante Teoria do Conhecimento, há a ressalva de que os textos clássicos serão apresentados após um texto explicativo "de um fôlego maior" sem apresentar que metodologia será utilizada em seu tratamento. A introdução do conteúdo estruturante Ética, não faz nenhuma menção à presença dos textos clássicos. Já nos próximos três conteúdos estruturantes - Filosofia Política, Filosofia da Ciência e Estética - a indicação é a mesma: serão tratados conceitos de alguns filósofos, sem indicar que textos serão utilizados.

O conteúdo estruturante de Estética é o que menos tem fragmentos de textos filosóficos. Aparecem variadas citações para ilustrar/complementar/legitimar os capítulos. Nos outros capítulos, os fragmentos de textos clássicos cumprem o papel de ilustrar/complementar/legitimar um discurso que é desenvolvido pelo autor ou autores dos mesmos.

Filosofia e Educação - ISSN 1984-9605 - v. 4, no 1, abril-setembro de 2012 
Apesar de sugerir/indicar a presença do texto filosófico, o que se observa é que o mesmo não é central no LDP. Os filósofos com maior número de fragmentos de textos são: Aristóteles, Maquiavel, Sartre, Platão, Rousseau, Descartes e Marx.

\section{Ensinar Filosofia a partir do texto}

Assim como não existe a Filosofia, mas há filosofias, também não há um caminho único para seu ensino, mas uma gama variada de caminhos que podem ser percorridos. Ainda que aceitemos o conceito de Filosofia como "desvendamento do mundo, das suas formas de manifestação, do significado profundo por trás das aparências das coisas" (CUNHA, 1992, p. 7), numa perspectiva que o torne universal, cada filósofo ou sistema o fará de um modo particular.

Essa visão de Cunha também é corroborada por Cossutta (2001, p. 6), quando diz que uma obra filosófica deve ser entendida como "um todo que se engendra e se desfaz, aberta ao mundo e ao sentido, mas igualmente redobrada sobre o universo que ela gera". Daí a dificuldade em compreender-se um texto filosófico dado à multiplicidade de filosofias, bem como, ainda na perspectiva do autor, o fato de que toda obra filosófica pretende construir as condições de sua própria validade por meio de regras de leitura que definem sua especificidade como gênero literário (COSSUTTA, 2001, p. 3). Assim, para se realizar uma leitura filosófica adequada de um texto filosófico, faz-se necessário

[...] explicitar as regras de funcionamento 9 que ligam os conceitos, as proposições, as argumentações, seja a partir das indicações, pistas, proposições explicitadas no próprio texto por seu autor, seja do exterior,

${ }^{9}$ Grifo no original.

Filosofia e Educação - ISSN 1984-9605 - v. 4, no 1, abril-setembro de 2012 
quando nós mesmos fazemos com que esses diferentes parâmetros variem (COSSUTTA, 2001, p. 7).

Porém "Uma coisa é verificar opiniões dos filósofos e descrevê-las; outra coisa bem diferente é debater com eles aquilo que dizem, e isto quer dizer do que falam" (HEIDEGGER, 1983, p. 19). Para tal debate, faz-se necessário investigar as ideias dos filósofos. Nesse sentido, Cunha (1992, p. 6) afirma que não se trata de uma investigação qualquer, mas uma investigação filosófica, ou seja,

Iniciando uma investigação filosófica, você estará participando do movimento de afirmação ou de negação dessa tradição (...) Incorporar-se na tradição filosófica implica, em um primeiro momento, adotar uma atitude filosófica diante dos textos que documentam essa tradição (p. 7).

Há um consenso sobre a presença do texto filosófico, diferenciando, é claro, com relação à importância do mesmo e como inseri-lo no contexto da sala de aula, em particular no nível Médio. Dos livros didáticos de Filosofia mais utilizados no Ensino Médio, o único que não faz uso de textos filosóficos é o Convite à Filosofia, de Marilena Chauí. Já o livro Filosofia, de Antonio Joaquim Severino, não somente faz uso de textos filosóficos, como indica uma metodologia de apropriação dos mesmos (1992, p. 14-15), além de indicar uma bibliografia complementar. Postura idêntica, aliás, tomada pelas autoras do Temas de Filosofia, Maria Lúcia de Arruda Aranha e Maria Helena Pires Martins (1992, p. 10-19), bem como por José Auri Cunha em seu livro Filosofia (1992, p. 2-20).

O LDP, como afirmamos anteriormente, não só não o coloca como central, mas também não aponta nenhuma orientação e/ou incentivo para seu uso nas aulas de Filosofia, a não ser no Portal Dia-a-dia Educação ${ }^{10}$,

${ }^{10} \mathrm{http}: / / \mathrm{www}$. filosofia.seed.pr.gov.br/

Filosofia e Educação - ISSN 1984-9605 - v. 4, no 1, abril-setembro de 2012 
onde são indicados alguns textos, com algumas observações gerais sobre o seu uso.

Trata-se agora, portanto, de sugerir algumas orientações sobre o uso do texto filosófico em sala de aula, de como proceder para uma leitura filosófica do mesmo, considerando a necessidade dessa prática tornar-se orgânica e sistemática nas aulas de Filosofia da escola pública brasileira, particularmente do Ensino Médio. O primeiro passo é o de contextualização, tanto do autor, histórica e filosoficamente, quanto do texto a ser lido. Isto porque, segundo Severino,

Um texto não pode ser abordado fora de seu contexto, fora das circunstâncias constituídas pelas malhas histórico-culturais que entrelaçam sentidos que foram sendo produzidos, amealhados e articulados ao longo do tempo histórico (2006, p. 76).

Feita a contextualização com os devidos cuidados, há que iniciar as leituras do texto escolhido. Isto porque, a leitura filosófica de um texto filosófico não se esgota numa primeira vez. Esta deve ser mais de aproximação, que de compreensão ou de interpretação. Segundo Lyotard, a atividade filosófica é um "exercício de paciência" (FABBRINI, 2005, p. 14). Como tal, há que serem feitas várias, não uma leitura, e ainda por cima aligeirada. Conforme o texto, há que se destacar alguns termos e esclarecêlos antes de iniciar um processo de investigação filosófica, buscando identificar qual o problema apresentado, a tese defendida pelo autor, bem como os argumentos que sustentam a mesma. Verificar a coerência e a consistência dos mesmos. Terminado este passo, é hora de fazer uma síntese crítica do mesmo, buscando verificar o nível de compreensão do texto para, quem sabe, uma retomada expositiva do texto por parte do professor. Cumpridos estes passos, o aluno estará em condições de produzir um texto

Filosofia e Educação - ISSN 1984-9605 - v. 4, no 1, abril-setembro de 2012 
em que ele retomarão as ideias discutidas, problematizando-as a partir de sua cotidianidade. Todo este processo deve ser cumprido de maneira dialogada e sem aligeiramento.

\section{Conclusão}

A partir do exposto até aqui, a título de conclusão, apresentamos a seguir duas sínteses que consideramos fundamentais:

1) A leitura e a análise do texto filosófico devem ser entendidas como elementos da mediação praxiológica dos conteúdos, oferecendo-se ao aluno condições teóricas básicas, possibilitando-lhe a superação da consciência passiva e ingênua e, em contraposição, suscitando-lhe o desenvolvimento de uma consciência crítica. Portanto, sem cair no formalismo textual, é fundamental capacitar o licenciando para a análise, a interpretação e o comentário de textos teóricos, segundo os procedimentos da técnica hermenêutica já consagrados. Isso pode ser feito através de oficinas de escrita e leitura filosóficas, que, desde o primeiro ano da licenciatura, aproximam gradualmente o aluno dos textos clássicos, desenvolvendo exercícios de leitura e documentação.

2) A leitura filosófica deve sugerir não um criticismo especulativo, discursivo e vazio que leva, geralmente, ao ceticismo, mas uma consciência crítica fruto da reflexão da própria experiência vivida em confronto com a cultura (conteúdos) que se transformará em experiência compreendida, ou seja, em um saber a respeito da própria experiência.

\section{Referências}

COSSUTTA, Frédéric. Elementos para a Leitura dos Textos Filosóficos. São Paulo: Martins Fontes, 2001.

CUNHA, José Auri. Filosofia: Iniciação à Investigação Filosófica. São Paulo: Atual, 1992.

Filosofia e Educação - ISSN 1984-9605 - v. 4, no 1, abril-setembro de 2012 
EVA, L. A. Entrevista concedida a Francisco de Araujo e Geraldo Balduino Horn. Curitiba, 25 de set. 2001.

FABBRINI, Ricardo Nascimento. O Ensino de Filosofia: A Leitura e o Acontecimento. 2005. Disponível:

http://www.scielo.br/pdf/trans/v28n1/29404.pdf. Acesso 16 mai. 2007. HEIDEGGER, Martin. Conferências e escritos filosóficos. Col. Os Pensadores. São Paulo: Abril Cultural, 1983.

HORN, Geraldo Balduino. Por uma mediação praxiológica do saber fillosófico no Ensino Médio: análise e proposição a partir da experiência paranaense. São Paulo: FEUSP, 2002. Tese de doutorado.

PARANÁ. Secretaria de Estado da Educação do Paraná. Diretrizes Curriculares da Educação Básica Filosofia. Paraná, 2008.

SEVERINO, Antonio Joaquim. A Importância do Ler e do Escrever no Ensino Superior. In: CASTANHO, Sérgio; CASTANHO, Maria Eugênia. Temas e Textos em Metodologia do Ensino Superior. Campinas/SP: Papirus, 2001. 182 p.

Filosofia e Educação - ISSN 1984-9605 - v. 4, no 1, abril-setembro de 2012 